DOI: 10.20472/IAC.2018.036.028

\author{
HINDINA MAULIDA \\ UIN SULTAN SYARIF KASIM RIAU, Indonesia
}

\title{
THE WOMAN CONTRIBUTION ON THE WELFARE: A CASE STUDY ON RELOCATED SEA NOMADS
}

\begin{abstract}
:
Southeast Asia is the home of Sea Nomads distinctive groups, called as Suku Laut. In Indonesia, some of the Sea Nomads already live in the relocated are but they live in poverty. To achieve the community welfare, it shall begin with the family prosperity that needs woman contributio. This paper investigates how woman participation improves the welfare of Duanu Tribe with the aim to understand how the stronger roles of women contribute to the welfare. Using case study method, the primary data were obtained from interviews with women ofDuanu Tribe, village head, Duanu tribal figures, and observations. Secondary datawere taken from UDHR documents, Indonesian government regulations, and other related research. The women of Duanu Tribe have not been able to maximally participate in improving the tribe welfare due to lack of education, low health degree, and culture that stimulates them to be unproductive and have multiple burdens when participating in the public sector. Therefore, there is in need of women's empowerment in order to realize the prosperity of the Duanu Tribe.
\end{abstract}

\section{Keywords:}

woman empowerment, welfare, sea nomads, duanu tribe, Riau 